\title{
Samambaias epífitas em trilhas do Parque Guairacá, município de Paula Freitas, Paraná
}

\author{
Epiphytic ferns in trails of the Guairacá Park, \\ municipality of Paula Freitas, Paraná state
}

Aysslan José Alves da Silva ${ }^{1}$, Rogério Antonio Krupek²

Resumo

Os epífitos desempenham importantes funções ecológicas, e em particular as samambaias, mostram uma diversidade significativa em ambientes florestais, ocupando microambientes específicos e diversos. A diversidade de samambaias epifíticas no estado do Paraná ainda é relativamente pouco conhecida. A região de Paula Freitas, em particular, não apresenta estudos específicos para este grupo de plantas. Neste sentido, o presente estudo teve por finalidade avaliar a riqueza de espécies de samambaias epífitas em regiões de trilhas no Parque Municipal Guairacá em Paula Freitas, Paraná. Foram registradas 10 espécies distribuídas em oito gêneros e quatro famílias. A família Polypodiaceae foi a mais rica na área avaliada (oito espécies), reflexo das características morfoanatômicas comuns às espécies da família. Os resultados encontrados contribuem com o reconhecimento das características florísticas e ecológicas de samambaias epífitas ocorrentes no estado do Paraná.

Palavras-chave: Pteridoflora. Ambientes epifíticos. Floresta ombrófila mista. Parques urbanos.

\begin{abstract}
Epiphytes play important ecological role, and the ferns shows a significant diversity in the forest environments, due to the numerous specific and diverse microenvironments. The diversity of epiphytic ferns in Paraná state is still relatively unknown. The Paula Freitas region, in particular, does not present specific studies for this group of plants. In this sense, the present study aimed to evaluate the diversity of epiphytic ferns in regions of trails in the Guairacá Municipal Park in Paula Freitas, Paraná. Ten species in eight genera and four families were recorded. The family Polypodiaceae (eight species) was the richest in the evaluated area, reflecting the morphoanatomic characteristics common to the family species. The results contribute to the recognition of the floristic and ecological characteristics of epiphytic ferns occurring in the state of Paraná.
\end{abstract}

Keywords: Pteridoflora. Epiphytic environments. Araucaria forest. Urban parks.

${ }^{1}$ Graduação em Biologia pela Universidade Estadual do Paraná (Unespar), União da Vitória, Paraná, Brasil.

${ }^{2}$ Doutorado em Biologia Vegetal pela Universidade Estadual Paulista Júlio de Mesquita Filho (Unesp), São Paulo, Brasil. Professor Adjunto da Universidade Estadual do Paraná, União da Vitória, Paraná, Brasil. E-mail: rogeriokrupek@yahoo.com.br 


\section{Introdução}

As samambaias e licófitas constituem um grupo relativamente diverso e abundante em ambientes tropicais, podendo representar até 15\% das espécies de plantas vasculares em formações florestais tropicais. ${ }^{(1,2)}$ No Brasil, estima-se que o domínio Mata Atlântica apresente a maior riqueza de espécies (cerca de 883 espécies), sendo a Região Sul (com predomínio da fitofisionomia de Floresta Ombrófila Mista - Floresta de Araucária) considerada uma das mais ricas (576 espécies estimadas). ${ }^{(3)}$ Além de tudo, as samambaias e licófitas destacam-se como um grupo de plantas que possui preferências variadas quanto ao hábitat e que se adaptam melhor aos ambientes sombreados com umidade relativa alta e rico em nutrientes, como os encontrados em fitofisionomias de Floresta de Araucária. ${ }^{(4)}$

Atualmente as plantas vasculares sem sementes são subdivididas em duas classes: Lycopodiopsida (licófitas) e Polypodiopsida (samambaias), sendo consideradas como linhagens distintas. ${ }^{(1)}$ As monilófitas e licófitas compõem um grupo de grande diversidade morfológica, podendo apresentar grandes diferenças entre os seus representantes. Muitas espécies apresentam caules subterrâneos e conjuntos de frondes profundamente lobadas ou compostas, providas de muitas nervuras e comparativamente grandes, embora representantes com rizomas longo-reptantes (p.ex. Microgramma spp.) e folhas micrófilas (licófitas) também ocorram. Incluem desde plantas arborescentes de vários metros até plantas com poucos centímetros, além de plantas aquáticas com folhas filiformes. ${ }^{(5)}$

Os epífitos podem ser definidos como organismos que vivem todo seu ciclo de vida ou parte dele sobre outras plantas, sem gerar prejuízos diretos à planta hospedeira, diferentemente do que fazem as plantas parasitas. As interações dos epífitos com seus hospedeiros podem ocorrer acidentalmente ou pelo fato de exercer uma função fisiológica importante, ${ }^{(6)}$ como, por exemplo, a disponibilização de espaço com maior incidência luminosa para a fotossíntese.
A importância ecológica do epifitismo nas comunidades florestais consiste basicamente na manutenção do equilíbrio e diversidade biológica. Espécies de samambaias epífitas proporcionam recursos alimentares e microambientes especializados para a fauna do dossel, através do armazenamento de consideráveis quantidades de biomassa associada à retenção de água e detritos tendo, portanto, grande desempenho na produtividade primária e ciclagem de nutrientes, além de funcionarem como hospedeiros em inúmeras interações com a fauna, até mesmo como bioindicadores ambientais. ${ }^{(7-9)}$

Este trabalho tem como objetivo registrar a pteridoflora epifítica em um fragmento de Floresta Ombrófila Mista (FOM) do Parque Municipal Guairacá na cidade de Paula Freitas, Região Sul do estado do Paraná. Considerando que não se tem informações a respeito da diversidade do grupo na Região, este trabalho traz as primeiras informações de ocorrência de espécies de samambaias epífitas na Região, gerando também conhecimento sobre a distribuição do grupo. Além disso, as informações podem servir como base para estudantes de biologia ou interessados em taxonomia de samambaias e licófitas.

\section{Material e Métodos}

\section{Área de estudo}

O município de Paula Freitas, Região Sul do estado do Paraná, Brasil, se estende por $420,3 \mathrm{~km}^{2}$ e conta com 5.430 habitantes conforme o último censo realizado. A densidade demográfica é de 12,9 habitantes por $\mathrm{km}^{2}$ no território do município. A cidade, situada em média a 793 m de altitude, tem as seguintes coordenadas geográficas: $26^{\circ} 12^{\prime} 09^{\prime \prime}$ a $26^{\circ} 12^{\prime} 26^{\prime \prime}$ Sul, 5056'24" a 5056'36" Oeste ${ }^{(10)}$ (Figura 1). 
Figura 1 - Localização da área de estudos (ponto verde) no município de Paula Freitas, Região Sul do estado do Paraná, Sul do Brasil. O retângulo indica o Parque Municipal Guairacá.

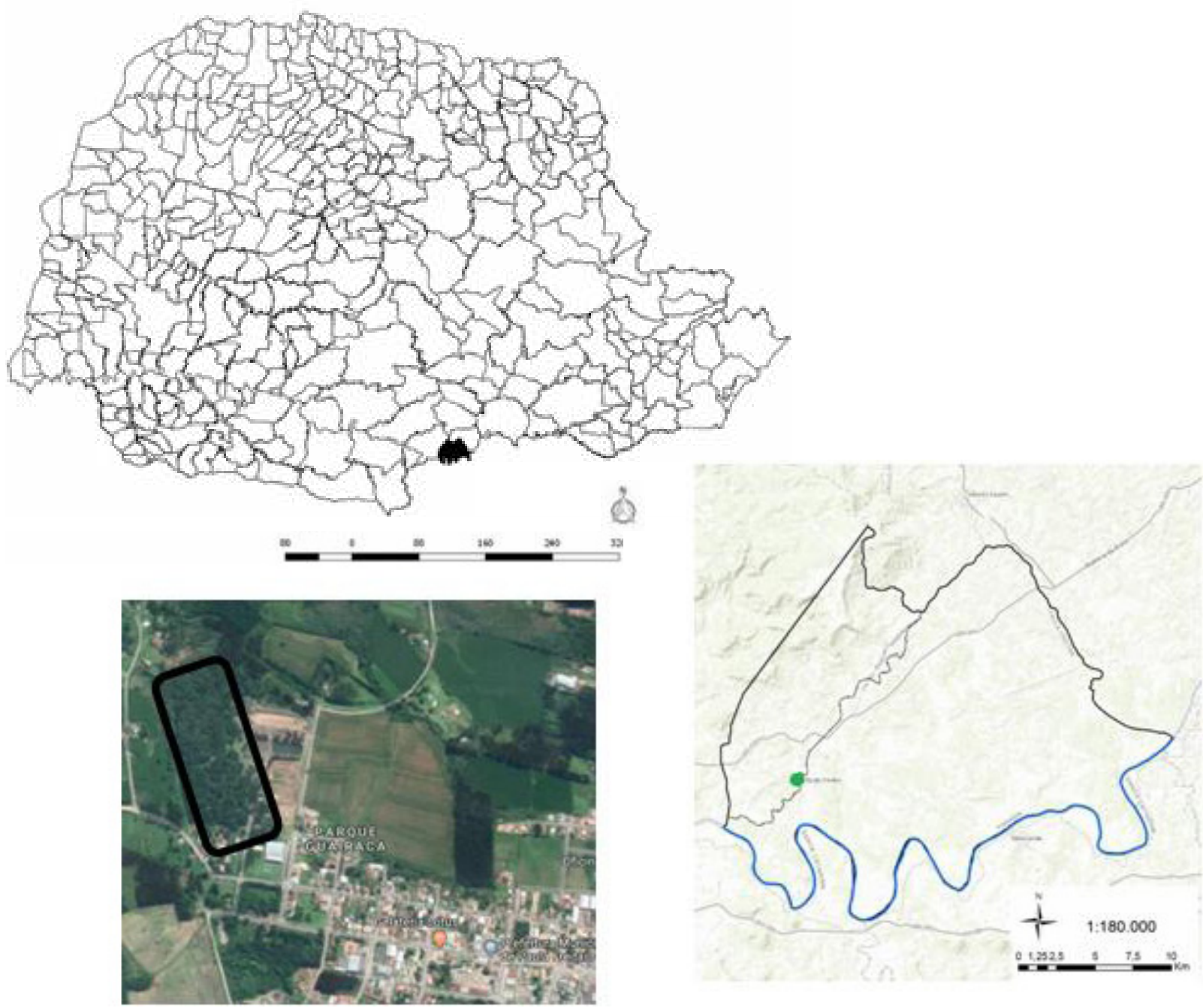

Fonte: Adaptado de Paraná(11)

O trabalho foi realizado no Parque Guairacá com área total de 13,2 ha situado na parte central da cidade. Parte da área é constituída de quiosques com churrasqueiras e estradas na parte periférica (inicial) do local. Da parte central à parte final, constitui-se de mata fechada e conservada, com pequenas trilhas e grande quantidade de Araucaria angustifolia (Bertol.) Kuntze (Figura 2).

$\mathrm{O}$ clima da região é do tipo $\mathrm{Cfb}$, segundo a classificação de Köeppen, ${ }^{(12)}$ o que implica em um clima mesotérmico, úmido a superúmido, sem estação seca, com verões frescos e geadas noturnas severas ocorrendo mais de cinco vezes por ano. Destaca-se a influência do Rio Iguaçu sobre o regime de chuvas, que se apresenta homogêneo durante todo o ano, não variando sensivelmente entre o trimestre mais seco e o trimestre mais chuvoso. A média anual de precipitação está na faixa de $1.600 \mathrm{a}$ $1.800 \mathrm{~mm}$. A média de temperatura anual é de $17^{\circ} \mathrm{a}$ $18^{\circ} \mathrm{C}$, chegando a médias de $13^{\circ}$ a $14^{\circ} \mathrm{C}$ no inverno e de $23^{\circ}$ a $24^{\circ} \mathrm{C}$ no verão. $\mathrm{O}$ tipo de solo predominante da região é o Cambissolo com 48,08\% da área total classificada da microbacia, seguido de Argissolo com 29,23\%, e Gleissolo com 18,28\%. . $^{(12)}$ As características de horizonte B textural dos Argissolos e pouca profundidade dos Cambissolos tornam estes solos susceptíveis à erosão, necessitando de práticas complementares de conservação de solo. ${ }^{(13)}$ 
Figura 2 - Imagens da área de estudos (Parque Municipal Guairacá) evidenciando as áreas internas (trilhas - A) e os locais de lazer (com maior perturbação antrópica - B, C e D).
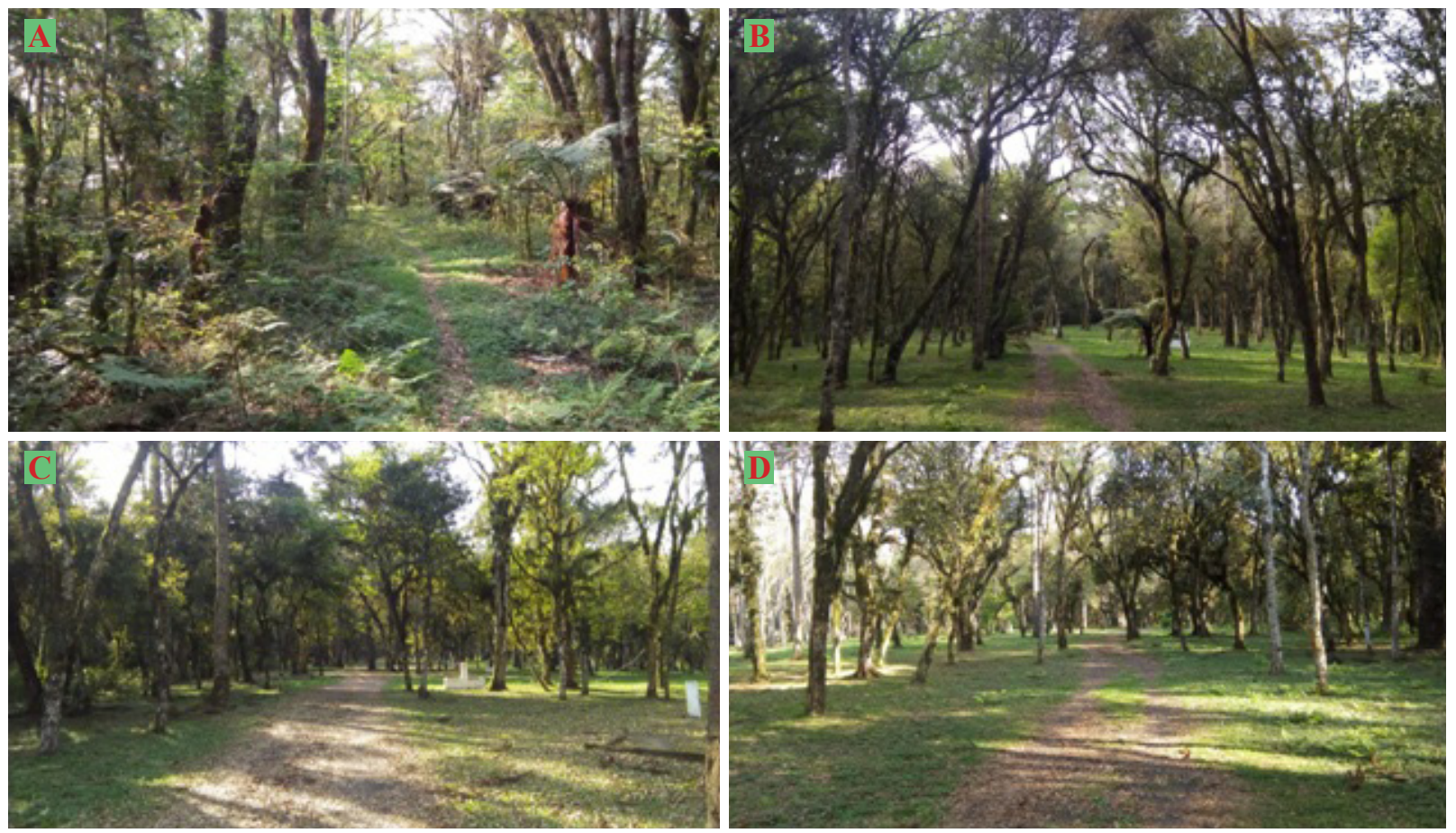

Fonte: Autores

\section{Delineamento amostral}

As coletas foram realizadas em toda área florestada, que consistiram em percorrer aleatoriamente todas as trilhas do parque. ${ }^{(14)}$ Foram amostradas três trilhas maiores $(>1,5 \mathrm{~km})$ e outras de percurso mais curto $(500 \mathrm{~m})$, observando o maior número possível de microambientes ocorrentes. Todas as plantas arbóreas localizadas nas bordas das trilhas foram averiguadas para a presença/ausência de samambaias e licófitas epífitas. As coletas de material foram mensais, sendo que o período se estendeu de agosto/2017 a julho/2018, perfazendo um ano.

As amostras de cada um dos táxons foram coletadas e herborizadas de acordo com a metodologia padrão para as plantas vasculares. ${ }^{(15)}$ A identificação do material botânico foi realizada utilizando-se de literatura especializada, com posterior tombo no Herbário Cachoeiras Vale do Iguaçu (HCVI). Para o tratamento taxonômico foi utilizado neste trabalho a circunscrição de PPG I. ${ }^{(1)}$
A abreviatura dos nomes dos autores das espécies seguiu Flora do Brasil 2020. ${ }^{(16)}$ Os dados referentes à distribuição geográfica dos táxons foram baseados nos trabalhos de Flora do Brasil 2020. (16-19) $^{(19}$

As samambaias e licófitas epífitas foram classificadas quanto ao tipo de relação com o forófito em categorias ecológicas, conforme proposto por Benzing:(20) holoepífitos habituais (presentes principalmente no ambiente epifítico); facultativos (ocorrem em ambiente epifítico como terrestre ourupícola); acidentais (preferencialmente terrestres); hemiepífitos secundários (germina no solo e, após estabelecimento do contato com o forófito, a porção basal do sistema radicial/ caulinar sofre degeneração).

Com o intuito de tornar o processo de identificação das espécies mais fácil e claro, principalmente para iniciantes em taxonomia de samambaias e licófitas, para cada informação de importância taxonômica utilizada na chave de identificação, são apresentadas imagens elucidativas das mesmas. Em adição, para cada 
táxon identificado são apresentadas descrições sucintas, imagens de campo e do material herborizado e demais características importantes à sua identificação.

\section{Resultados e Discussão}

\section{Caracterização ecológica da comunidade epifítica}

$\mathrm{Na}$ área de estudos foram encontradas 10 espécies de samambaias epífitas, todas pertencentes ao clado das Monilófitas. As espécies foram distribuídas em três famílias: Aspleniaceae, Pteridaceae (uma espécie cada) e Polypodiaceae (oito espécies).

A riqueza de espécies de samambaias epífitas encontrada na área de estudo está de acordo com os valores encontrados em outros estudos (p.ex. Bataghin et al., ${ }^{(21)} 6$ espécies; Geraldino et al., ${ }^{(22)}$ 10 espécies), embora alguns trabalhos tenham encontrado valores maiores de riqueza (p.ex. Barros et al..$^{(23)}$ - 16 espécies; Fraga et al. ${ }^{(24)}$ - 20 espécies; Kersten \& Kuniyoshi ${ }^{(25)}$ - 27 espécies). Também foram registrados maior número de espécies de samambaias epífitas em um único tipo de planta hospedeira, como no caso de Alsophila setosa Kaulf. (com 14 espécies) ${ }^{(26)}$ e Dicksonia sellowiana Hook. (com 20 espécies), ${ }^{(23)}$ ambas samambaias arborescentes. Tais espécies são muito particulares com relação às características morfológicas de seus cáudices (densa camada de raízes adventícias - D. sellowiana ou bases remanescentes de pecíolo - $A$. setosa) e propiciam um micro-habitat distinto e favorável ao desenvolvimento de epífitos. ${ }^{(23,27)}$ A ausência de samambaias arborescentes nas áreas avaliadas pode ter contribuído para a relativa baixa riqueza de epífitos observada em relação a estes estudos.

Outro fator que pode explicar a riqueza de espécies observadas refere-se aos habitats avaliados neste estudo (regiões de trilhas), os quais apresentam características particulares (alterados antropicamente) e, consequentemente, geram uma flora hospedeira comparativamente mais limitada quando comparado a regiões de floresta fechada. Embora plantas epífitas vasculares apresentem adaptações morfofisiológicas relacionadas às variações de umidade, luminosidade e temperatura a que estão submetidas, sua sobrevivência está fortemente associada ao estresse hídrico. ${ }^{(1,28,29)}$ As samambaias, em particular, são plantas tipicamente de ambientes sombreados e úmidos, e áreas de trilhas, como as analisadas neste estudo, podem gerar maiores variações ambientais (principalmente de temperatura e umidade) afetando diretamente o número de espécies ocorrentes.

Segundo Kira e Yoda, ${ }^{(30)}$ variações de temperatura e umidade podem ser minimizadas através de adaptações específicas. Neste sentido, para as samambaias epífitas podemos citar características tais como o rizoma filiforme, sistema radicial reduzido, frondes pequenas, coriáceas ou com tricomas, ponto de saturação luminoso baixo, alta tolerância à escassez nutricional, dispersão anemófila de esporos. ${ }^{(20,27,30-32)}$ Considerando as plantas coletadas nas trilhas do parque Guairacá, percebem-se tais características morfológicas nitidamente, na maioria das espécies. Somado a isto, Geraldino et al. ${ }^{(21)}$ citam espécies comuns a este estudo (p.ex. Microgramma squamulosa (Kaulf.) de la Sota e Pleopeltis hirsutíssima (Raddi) de la Sota) como sendo plantas pioneiras e diagnósticas de ambientes mais perturbados, como florestas secundárias. Além disso, algumas espécies aqui descritas (Campyloneurum nitidum (Kaulf) C. Presl, M. squamulosa, P. hirsutissima, P. pleopeltifolia (Raddi) Alston) também foram registradas por Alves et al. ${ }^{(33)}$ em levantamento de epífitos vasculares em áreas urbanas de Palmeira das Missões, RS, ambiente considerado altamente alterado antropicamente. Em contrapartida, algumas espécies registradas (p.ex. Asplenium gastonis Fée e Plebodium pseudoaureum (Cav.) Lellinger) são comumente descritas para ambientes altamente preservados como áreas de proteção ambiental. ${ }^{(20,34,35)}$ Tais resultados reforçam as características microambientais variáveis encontradas em regiões de trilhas e 
que podem prover a formação de comunidades amplamente divergentes quanto às suas necessidades biológicas.

O número de famílias registrado está de acordo com outros estudos similares (p.ex. 6 famílias; ${ }^{(21)} 2$ famílias; ${ }^{(22)} 7$ famílias; ${ }^{(23)} 3$ famílias; ${ }^{(24)} 6$ famílias, ${ }^{(25)}$ incluindo Lycopodiaceae, 2 famílias ${ }^{(33)}$ ), embora a maioria destes estudos tenha tratado de epífitos vasculares em geral, incluindo demais grupos taxonômicos e não especificadamente samambaias. Neste sentido, todos os estudos acima citados (exceto $^{(23)}$ ) encontraram Polypodiaceae como as samambaias epífitas melhor representadas. A família é cosmopolita e uma das mais diversificadas $( \pm 1.600$ espécies), sendo extremamente rica e abundante, principalmente em regiões tropicais. ${ }^{(17)} \mathrm{A}$ família apresenta muitas espécies adaptadas ao epifitismo (p.ex. alta plasticidade fenotípica, elevada viabilidade dos esporos) contribuindo para sua alta representatividade neste tipo de habitat. ${ }^{(21,36,37)}$ Aspleniaceae (neste estudo, com uma espécie registrada) também se destaca como comum em habitats epifíticos. . $^{(23,38)}$

A distribuição das espécies epifíticas dentro das categorias ecológicas evidenciou predomínio de holoepífitos habituais $(90,9 \%$ do total), sendo que apenas Pteris lechleri Mett $(9,1 \%)$, foi classificada como holoepífita acidental. Esta espécie apresenta frondes geralmente grandes (>30 cm de comprimento), o que pode dificultar o estabelecimento do hábito epifítico, sendo comumente registrada como terrícola. ${ }^{(34,35)}$ As demais espécies geralmente ocorrem como epífitas e a presença de adaptações relacionadas à variação climática típica destes microambientes tem influenciado no sucesso destas espécies (p.ex. frondes simples e coriáceas em Campyloneurum nitidum e C. austrobrasilianum - nesta espécie extremamente filiforme; caules alongados tipo estolonífero em Microgramma squamulosa; presença de tricomas e escamas em abundância em Pleopeltis hirsutissima; e alta resistência a dessecação em Pleopeltis pleopeltifolia).

\section{Chave de identificação para as espécies de samambaias epífitas do Parque Municipal Guairacá}

1. Plantas com frondes simples..............................2

1. Plantas com frondes pinatífidas ou pinadas.......4

2. Plantas com frondes dimorfas

Micrograma squamulosa

2. Plantas com frondes monomorfas.......................3

3. Lâmina até $1,0 \mathrm{~cm}$ de largura, nervuras laterais não visíveis e com pontuações brancas na face adaxial............Campyloneurum austrobrasilianum 3. Lâmina maior que $1,0 \mathrm{~cm}$ delargura, com nervuras laterais evidentes, sem pontuações brancas na face adaxial Campyloneurum nitidum

4. Face abaxial da lâmina com soros lineares.......5

4. Face abaxial da lâmina com soros arredondados 6

5. Soros dispostos sobre as nervuras secundárias... Asplenium gastonis

5. Soros dispostos na margem da folha.

Pteris lechleri

6. Superfície adaxial da lâmina glabra ou com tricomas inconspícuos....Plebodium pseudoaureum 6. Superfície adaxial da lâmina pilosa ou escamosa

\section{7}

7. Lâmina com nervuras livres, evidentes..............8

7. Lâmina com nervuras anastomosadas, ocultas....

\section{9}

8. Lâmina membranácea, pinatissecta, ovadas a lineares, ápice agudo a atenuado, segmentos basais fortemente deflexos..........Pecluma pectinatiformis 8. Lâmina subcoriácea, pinada na base, pinatissecta na região mediana até o ápice, oblongo-lanceolada e terminando em um segmento alongado, segmentos basais perpendiculares à raque......Pecluma singeri 9. Pinas com mais de 20 pares de segmentos; segmentos com uma aurícula na face acroscópica basal. .Pleopeltis hirsutissima 9. Pinas com menos de 10 pares de segmentos; segmentos sem uma aurícula na face acroscópica basal. Pleopeltis pleopeltifolia 


\section{Descrição das espécies}

Asplenium gastonis Fée, Crypt. Vasc. Brésil 1: 70, tab. 19, fig. 2. 1869. Figura 3 A.

Caule ereto, com escamas lanceoladas, não clatradas, castanhas, margem inteira e ápice agudo. Frondes monomorfas, pendentes. Pecíolo sulcado adaxialmente, fosco e portando esparsas escama lineares, castanhas. Lâmina deltoide-lanceolada, 2-pinado-pinatífida. Pinas longo atenuadas e pínulas obovadas, margem denteada e nitidamente pecioluladas até quase o ápice da pina; superfície adaxial glabra e abaxial com escamas lineares, castanho-escuras; nervuras livres, bifurcadas. Soros inframedianos, elípticos e com indúsio coriáceo, claro e de margem inteira.

Categoria ecológica: holoepífito habitual.

Distribuição: Paraguai, Argentina, Uruguai e Brasil, nos estados de Minas Gerais, São Paulo, Paraná, Santa Catarina e Rio Grande do Sul. ${ }^{(17)}$

Comentários: esta espécie pode apresentar mais de um tipo de hábito, sendo que a mesma foi descrita por Michelon ${ }^{(39)}$ ocorrendo como terrícola, rupícola e epífita no Parque Estadual do Guartelá, Paraná.

Asplenium gastonis foi tratada por Sylvestre $^{(40)}$ como possuindo frondes dimorfas, característica utilizada para diferenciar esta espécie de A. auritum. Entretanto, isto não foi observado por Michelon, ${ }^{(39)}$ sendo esta característica considerada variável dentro da espécie. Como característica particular, A. gastonis apresenta as lâminas 2-pinado-pinatífida e a presença de pínulas pecioluladas desde a base até próximo à região apical da fronde.

Material examinado: HCVI 746.

Campyloneurum austrobrasilianum (Alston) de la Sota, Op. Lilloana 5: 99. 1960. Figura 3 B.

Caule curto-reptante, com escamas lanceoladas, clatradas, castanho-claras, margem lisa e ápice atenuado. Frondes monomorfas, eretas a pendentes. Pecíolo sulcado, curto a longo com escamas iguais às do caule. Lâmina simples, linear, base decurrente, ápice atenuado e margens revolutas, coriácea, glabra; nervuras anastomosadas formando duas fileiras de aréolas entre a costa e a margem. Soros redondos, formando uma fileira entre a costa e a margem.

Categoria ecológica: holoepífito habitual.

Distribuição: Brasil, nos seguintes estados: Minas Gerais, São Paulo, Rio de Janeiro, Paraná, Santa Catarina e Rio Grande do Sul. ${ }^{(17)}$

Comentários: Para Silva e Schwartsburd ${ }^{(19)}$ Campyloneurum austrobrasilianum forma juntamentecom Campyloneurum centrobrasilianum Lellinger(que ocorre na região Centro-Oeste e Norte do Brasil) e com Campyloneurum angustifolium (Sw.) Fée (registrado em várias regiões do Brasil) o complexo Campiloneurum angustifolium, sendo que a principal diferença entre estas espécies são as características das escamas caulinares. Em $C$. austrobrasilianum as escamas do caule apresentam a base formada por duas aurículas assimétricas. ${ }^{(41)}$

Material examinado: HCVI 749.

Campyloneurum nitidum (Kaulf.) C. Presl, Tent. Pterid. 190. Fig. 1 C, 1836. Figura 3 C.

Caule curto-reptante, com escamas não clatradas, castanhas, orbiculares, margens inteiras. Frondes monomorfas, eretas a pendentes. Pecíolo ausente ou muito curto, sulcado e alado, verdeamarelado. Lâmina lanceolada, longamente atenuada para a base e menos para o ápice, cartácea a coriácea, margens inteiras. Nervuras anastomosadas, aréolas em 4-7 fileiras entre a costa e a margem da lâmina. Soros redondos, localizados no ápice das vênulas inclusas, 4-7 séries em cada lado da costa.

Categoria ecológica: holoepífito habitual.

Distribuição: Argentina, Paraguai, Uruguai e Brasil, nos estados de São Paulo, Santa Catarina, Rio de Janeiro, Paraná e Rio Grande do Sul. ${ }^{(16,17)}$

Comentários: esta espécie tem sido confundida com Campyloneurum phyllitidis, mas difere desta última por serem plantas menores (lâmina com 25-75 cm de comprimento), com caule delgado (3-4 $\mathrm{mm}$ de largura), ápice da lâmina atenuado e escamas do rizoma com ápice arredondado. Enquanto Campyloneurum 
phyllitidis apresenta lâmina com $60-150 \mathrm{~cm}$ de comprimento, caule robusto (6-15 $\mathrm{mm}$ de largura), ápice da lâmina caudado ou acuminado e escamas do rizoma com ápice acuminado. ${ }^{(19,41)}$ Os espécimes encontrados no Parque Municipal Guairacá estão de acordo com as medidas descritas acima para Campyloneurum nitidum.

Material examinado: HCVI 751.

Figura 3 - A. Asplenium gastonis; B. Pleopeltis pleopeltifolia; C. Campyloneurum nitidum; D. Pleopeltis hirsutissima; E. Campyloneurum austrobrasilianum; F. Microgramma squamulosa. Escala $=5 \mathrm{~cm}$.
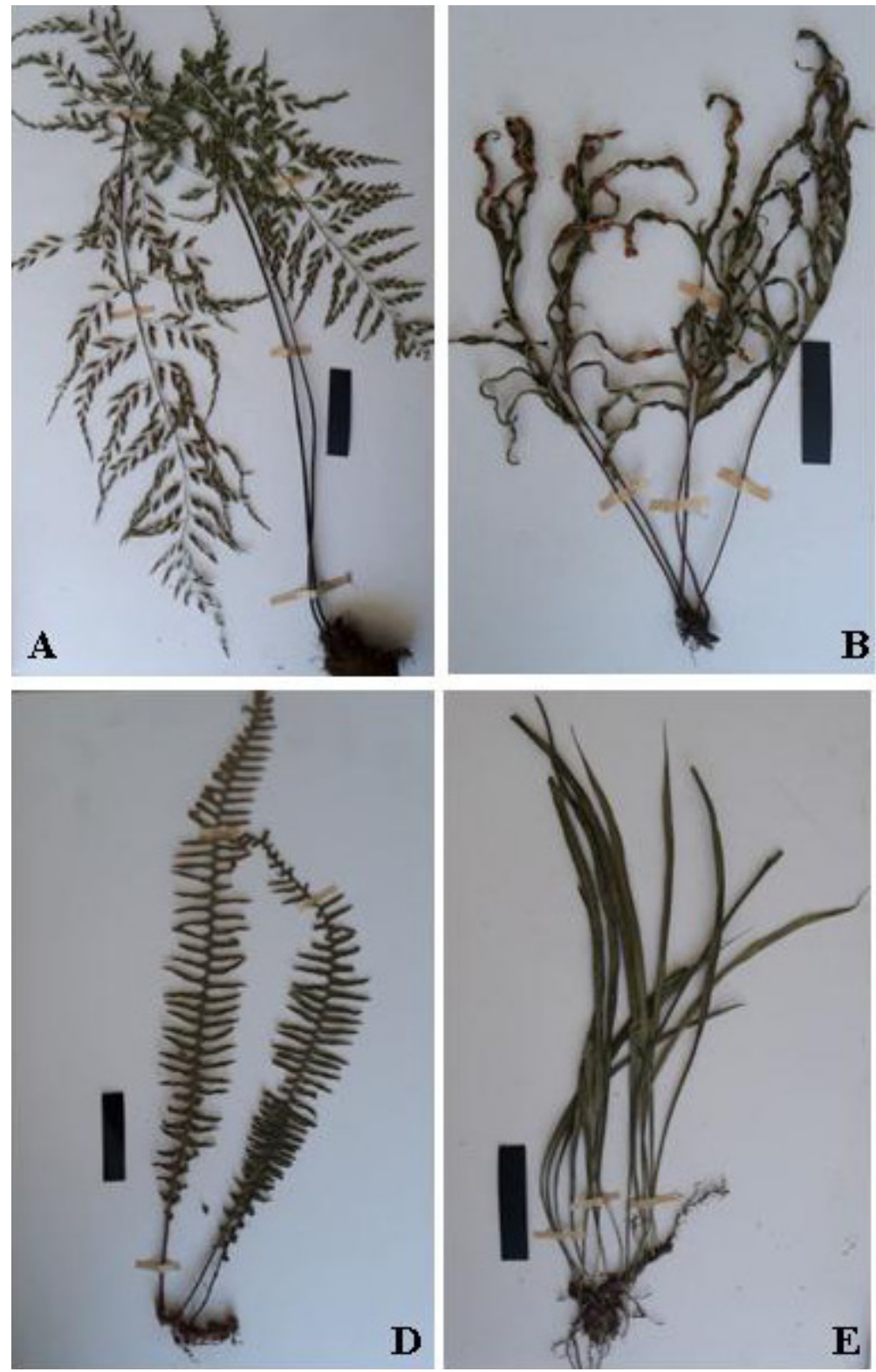
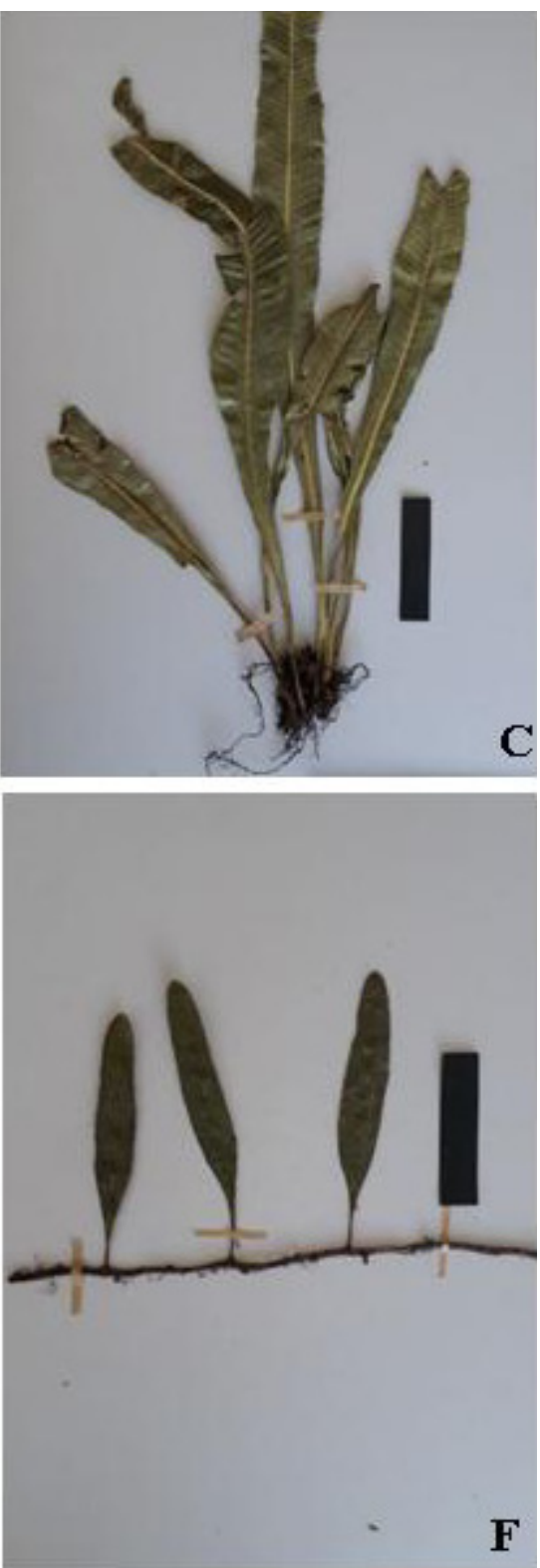

Fonte: Autores

Pleopeltis hirsutissima (Raddi) de la Sota, Darwiniana 45(2): 239. 2008 Figura 3 D.

Caule longo-reptante, com escamas subclatradas, castanho-claras, lanceoladas a ovadolanceolada, margem ciliada e ápice filiforme.
Frondes monomorfas, eretas. Pecíolo cilíndrico, castanho-escuro. Fronde coriácea, 1-pinada, linearlanceolada, revestidas de escamas subclatradas, lanceoladas a ovado-lanceoladas, dispostas sobre a raque e costa (em ambas as superfícies da lâmina), 
escamas em ambas as superfícies da lâmina, abaxialmente recobrindo quase que totalmente o tecido laminar. Pinas com uma aurícula no lado acroscópico da base, portando um aeróforo; nervuras ocultas. Soros redondos, circundados de escamas da lâmina.

Categoria ecológica: holoepífita habitual.

Distribuição: Argentina, Paraguai, Uruguai

e Brasil, nos seguintes estados: Bahia, Mato Grosso, Minas Gerais, Rio de Janeiro, São Paulo, Paraná, Santa Catarina e Rio Grande do Sul. ${ }^{(17)}$

Comentários: Planta muito comum na região de estudos, sendo encontrada tanto em ambientes naturais quanto antropizados. Pode ser facilmente reconhecida pela densa cobertura escamosa na face abaxial da lâmina, conferindo uma coloração ferrugínea à mesma. Embora outros autores tenham registado frondes de aproximadamente 50 pares de pinas e comprimento variando entre $21-43 \mathrm{~cm}\left(\right.$ p.ex. $\left.{ }^{(42)}\right)$, na área de estudos foi verificada uma alta variação para estes caracteres (frondes com 17-30 pares de pinas e comprimento de $8-13 \mathrm{~cm}$ ). Tal variação morfológica deve provavelmente refletir a alta variação de habitats presentes na área amostrada.

Material examinado: HCVI 748.

Pleopeltis pleopeltifolia (Raddi) Alston, Bol. Soc. Broteriana 30: 21. 1956. Figura 3 E.

Caule curto-reptante, com escamas subclatradas, negras, lanceoladas, margens laceradas, hialinas, ápice agudo. Frondes monomorfas, eretas. Pecíolo canaliculado na face adaxial, castanho-escuro, com duas aletas clorofiladas decurrentes à lâmina. Lâmina cartácea, pinatissecta ou bifurcada, com cerca de cinco segmentos, revestida por escamas subclatradas, lanceoladas a ovado-lanceoladas, esparsas sobre a costa, nervuras e tecido laminar (em ambas as superfícies da lâmina), aeróforos ausentes; nervuras ocultas. Soros redondos.

Categoria ecológica: holoepífito habitual.

Distribuição: Argentina, Uruguai, Paraguai e Brasil, nos estados de Goiás, Minas Gerais, São Paulo, Mato Grosso, Mato Grosso do Sul, Ceará,
Pernambuco, Bahia, Rio de Janeiro, Espírito Santo, Paraná, Santa Catarina e Rio Grande do Sul. ${ }^{(17)}$

Comentários: muito comum tanto em ambientes naturais quanto alterados na região de estudo. Pode ser diferenciada de outras espécies similares (p.ex. Pleopeltis polypodioides (L.) Andrews \& Windham e Pleopeltis pleopeltidis (Fée) de la Sota) por apresentar segmentos marcadamente oblíquos à raque e pela lâmina com aspecto palmatilobado.

Material examinado: HCVI 754.

Microgramma squamulosa (Kaulf.) de la Sota, Opera Lilloana 5: 59, fig. 2, 3, 6, 7. 1961. Figura $3 \mathrm{~F}$.

Caule longo-reptante, com escamas não clatradas, castanho-escuras ou castanho-claras, ovado-lanceoladas, de base auriculada e ápice agudo, margens ciliadas. Frondes dimorfas. Pecíolo curto a longo, levemente alado, com escamas esparsas, castanho-claras, geralmente ovadas, base arredondada, ápice acuminado. Lâmina estéril elíptica a lanceolada, base atenuada, ápice agudo a arredondado, lâmina fértil linearlanceolada, base atenuada, ápice agudo, às vezes levemente arredondado; nervuras areoladas, com 1-2 vênulas livres inclusas nas aréolas, visíveis.

Soros redondos a oblongos, medianos.

Categoria ecológica: holoepífita habitual.

Distribuição: Peru, Paraguai, Uruguai, Argentina e Brasil, nos seguintes estados: Espírito Santo, Minas Gerais, Rio de Janeiro, São Paulo, Mato Grosso, Mato Grosso do Sul, Bahia, Paraná, Santa Catarina e Rio Grande do Sul. ${ }^{(16-18)}$

Material examinado: HCVI 753.

Phlebodium pseudoaureum (Cav.) Lellinger, Amer. Fern J. 77: 101. 1987. Figura 4 A.

Caule curto rastejante, recoberto com escamas não clatradas, castanho-claras a alaranjadas, ovado-lanceoladas a linear-lanceoladas, base cordada ou levemente truncada, ápice filiforme. Frondes monomorfas, patentes. Pecíolo sulcado na face adaxial, castanho, lustroso. Lâmina cartácea, pinatissecta, oval, com a base truncada, glabra; 
segmentos patentes a ascendentes; nervuras não atingindo a margem dos segmentos. Soros redondos, dispostos em uma fileira entre a cóstula e a margem do segmento.

Categoria ecológica: holoepífito habitual.

Distribuição: EUA, México, Guatemala, Honduras, El Salvador, Nicaraguá, Costa Rica, Panamá, Grandes e Pequenas Antilhas, Colômbia, Venezuela, Trinidad, Guiana, Suriname, Guiana Francesa, Equador, Peru, Bolívia, Argentina, Paraguai e Brasil, nos seguintes estados: Mato Grosso, Mato Grosso do Sul, Goiás, Minas Gerais, Rio de Janeiro, Espírito Santo, São Paulo, Paraná, Santa Catarina e Rio Grande do Sul. ${ }^{(17)}$

Comentários: Silva e Schwartsburd ${ }^{(19)}$ encontraram exemplares com número de pinas em número de 4-13 pares, enquanto neste estudo, o único exemplar encontrado apresenta apenas dois pares de pinas (possivelmente um exemplar jovem). Todas as demais características diagnósticas (acima descritas) estão de acordo com o descrito por estes autores.

Material examinado: HCVI 752.

Pecluma pectinatiformis (Lindm.) M. G. Price, Amer. Fern J. 73(4): 115. 1983. Figura 4 B.

Caule curto a longo-reptante, com escamas não clatradas, linear-deltoides, margem inteira, ápice agudo. Frondes monomorfas. Pecíolo com tricomas aciculares e dourados. Lâmina elíptica, pinatissecta, base cuneada, ápice agudo; segmentos linear-deltoides, base assimétrica com o lado basiscópico perpendicular à raque, segmentos basais reflexos, reduzidos ou auriculiformes; superfície adaxial com tricomas aciculares sobre a raque, costa, margem dos segmentos e nervuras; superfície abaxial com tricomas aciculares sobre a raque, costa e nervuras; tricomas clavados no tecido laminar; nervuras livres, bifurcadas. Soros supramedianos, redondos, paráfises clavadas presentes.

Categoria ecológica: holoepífita habitual.

Distribuição: Argentina, Paraguai e Brasil, nos seguintes estados: Minas Gerais, Rio de Janeiro e São Paulo. ${ }^{(16,17)}$
Comentários: As frondes dos exemplares encontrados na área de estudos apresentaram tamanho comparativamente menor (10 a $30 \mathrm{~cm}$ de comprimento) daquele descrito em outros estudos (p.ex. 40 a $80 \mathrm{~cm} ;{ }^{(43)} 22$ a $55 \mathrm{~cm}^{(16)}$ ).

Material examinado: HCVI 755.

Pecluma singeri (de la Sota) M. G. Price, Amer. Fern J. 73: 115. 1983. Figura 4 C.

Caule curto-reptante, com escamas não clatradas, castanho-escuras, ovado-lanceoladas, levemente truncadas, margem inteira, ápice filiforme. Frondes monomorfas. Pecíolo castanhoescuro, com tricomas simples e/ou ramificados, ambos hialinos, levemente castanho-avermelhados. Lâmina subcoriácea, pinada na base, pinatissecta no ápice, oblongo-lanceolada, abruptamente atenuada e terminando em segmentos auriculiformes na base; nervuras geralmente 1-furcada, às vezes simples no ápice dos segmentos, inconspícuas, terminando próximas à margem da lâmina. Soros redondos, submarginais; paráfises simples, clavadas.

Categoria ecológica: holoepífito habitual.

Distribuição: Paraguai, Argentina e Brasil, nos estados de Minas Gerais, São Paulo, Paraná, Bahia, Santa Catarina e Rio Grande do Sul. ${ }^{(17)}$

Comentários: Segundo de la Sota, ${ }^{(44)}$ esta espécie difere das outras basicamente pela forma de crescimento de seu caule, curto-reptante, ereto, com duas fileiras de cicatrizes foliares evidentes e frondes aglomeradas no extremo superior.

Material examinado: HCVI 745.

Pteris lechleri Mett., Fil. Lechl. 2: 13. 1859. Figura 4 D.

Caule subereto, com escamas castanhoescuras, deltoides, margem fimbriada, base truncada e ápice acuminado. Frondes monomorfas, pendentes. Pecíolo com dois sulcos na superfície adaxial, castanho-escuro na base clareando em direção ao ápice. Lâmina 1-pinado-pinatífida, ovado-lanceolada, ápice acuminado; pinas opostas, sésseis, margem serreada, ápice acuminado; superfícies adaxial e abaxial com tricomas multicelulares, longos, aciculares, translúcidos; 
nervuras parcialmente areoladas. Soros lineares, marginais, pseudo-indúsio presente.

Categoria ecológica: holoepífita acidental.

Distribuição: Panamá, Colômbia, Equador, Peru, Bolívia e Brasil, nos seguintes estados: Minas Gerais, Rio de Janeiro e São Paulo. ${ }^{(17)}$

Comentários: não foram encontrados indivíduos férteis desta espécie, entretanto, a mesma foi identificada a partir das demais características diagnósticas acima e ao lado descritas e pela sua forma característica. A ausência de estruturas de reprodução pode estar relacionada com o ambiente em que a mesma foi observada, por não se tratar de uma espécie epífita típica.

Material examinado: HCVI 750.

Figura 4 - A. Plebodium pseudoaureum; B. Pecluma singeri; C. Pecluma pectinatiformis; D. Pteris lechleri. Escala $=5 \mathrm{~cm}$.
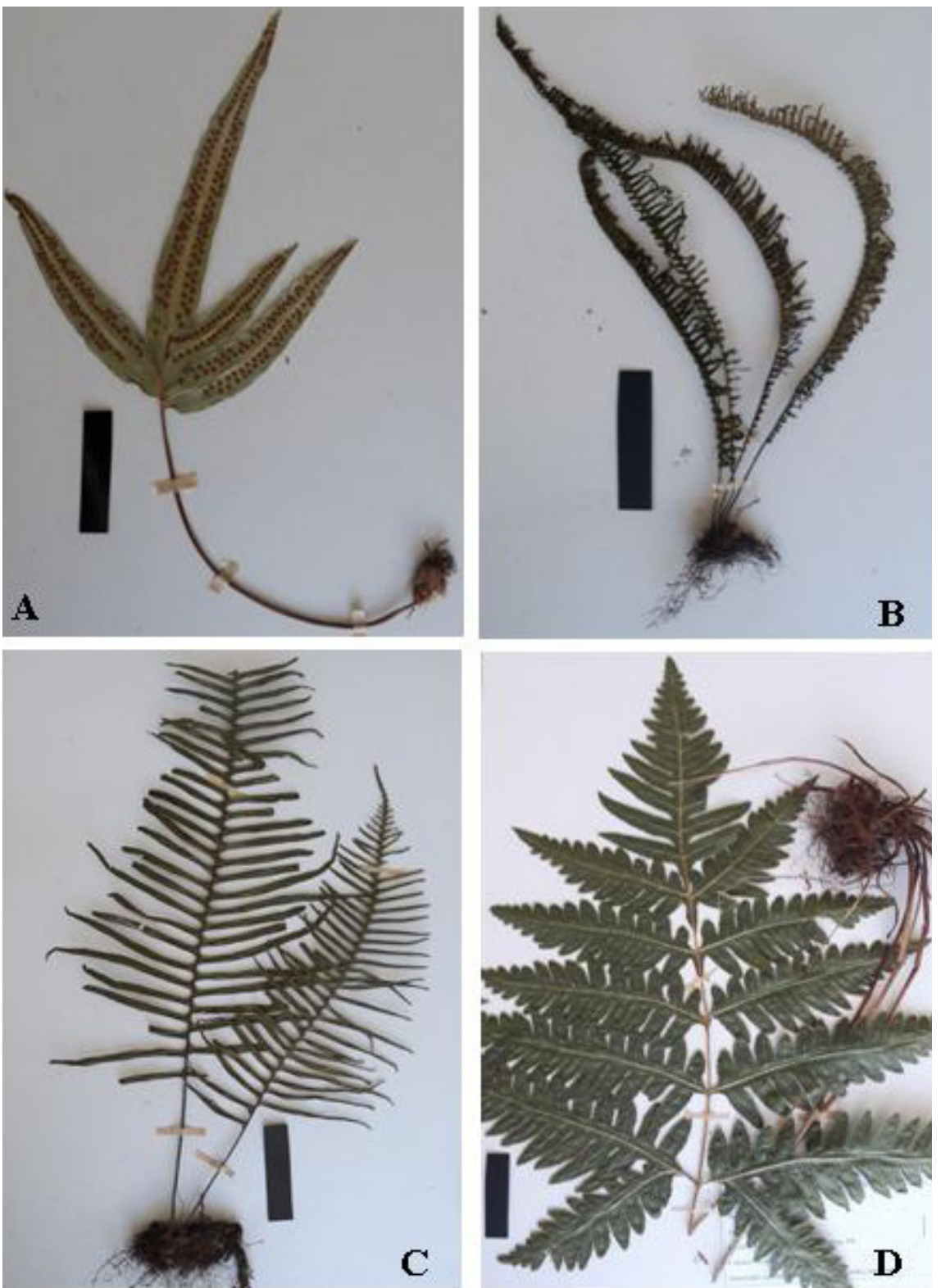

Fonte: Autores 


\section{Conclusão}

Considerando que a Floresta Ombrófila Mista abriga uma considerável diversidade de plantas arbóreas e que estas servem como substrato para plantas epifíticas e em especial para samambaias, o reconhecimento da flora epífita ocorrente nestes ambientes torna-se relevante. Os resultados aqui apresentados compreendem um primeiro registro para este grupo de plantas na região e podem auxiliar no desenvolvimento de ações conservacionistas futuras, principalmente considerando ambientes naturais preservados e de uso comum, como o Parque Municipal Guairacá em Paula Freitas, que propiciam a manutenção de redutos florestais importantes para espécies vegetais.

\section{Referências}

1 Pteridophyte Phylogeny Group. A communityderived classification for extant lycophytes and ferns. J Syst Evol. 2016;54:563-603. doi: $10.1111 /$ jse. 12229 .

2 Poulsen AD, Nielsen IH. How many ferns are there in one hectare of Tropical Rain Forest? Am Fern J. 1995;85(1):29-35. doi: $10.2307 / 1547678$.

3 Prado J, Sylvestre LS, Labiak PH, Windisch PG, Salino A, Barros ICL, et al. Diversity of ferns and lycophytes in Brazil. Rodriguésia 2015;66(4):1073-83. doi: 10.1590/21757860201566410 .

4 Bittencourt S, Corte APD, Sanqueta CR. Estrutura da comunidade de Pteridophyta em uma Floresta Ombrófila Mista, sul do Paraná, Brasil. Silva Lus. 2004;12(2):243-54.

5 Manfro P, Cardoso N. Levantamento preliminar de pteridófitas epífitas do campus central da PUCRS. In: Anais do 11 Salão de Iniciação Científica; 2010. Porto Alegre: PUCRS; 2010.

6 Benzing DH. Vascular epiphytism: taxonomic participation and adaptative diversity. Ann Mo Bot Gard. 1987;74(2):183-204. doi: 10.2307/2399394.
7 Coimbra-Filho AF, Aldrighi AD. Restabelecimento da fauna no Parque Nacional da Tijuca (Segunda contribuição). Brasil Florest. 1972;3(11): 19-33.

8 Nadikarni NM. An ecological overview and checklist of vascular epiphytes in the Monteverde Cloud Forest Reserve, Costa Rica. Brenesia 1985; 24: 55-62.

9 Benzing HD. Vascular epiphytes. In: Lowman MD, Nadikarni NM, editors. Forest Canopies. New York: Academic Press; 1995. p. 225-251.

10 Cidades Brasil. Município de Paula Freitas. [Internet]. 2017 [citado 2017 jun 19]. Disponível em: http://www.cidade-brasil.com. br/municipio-paula-freitas.html

11 Monastirsky LB, coordenador. Projeto Atlas eletrônico do antigo complexo ferroviário. [Internet]. 2017. [citado 2019 jun 5]. Disponível em: https://atlasparanatradicional. wordpress.com/hidrovia/paula-freitas-2/

12 Peel MC, Finlayson BL, Mcmahon TA. Updated world map of the Köppen-Geiger climate classification. Hydrol Earth Syst Sci. 2007;11:1633-44. doi: 10.5194/hess-11-16332007.

13 Instituto Agronômico do Paraná. Monitoramento Agroclimático do Paraná [Internet]. 2000. [citado 2019 jun 5]. Disponível em: www.iapar.com.br

14 Filgueiras TDS, Nogueira PE, Brochado AL, Guala GF. Caminhamento: um método expedito para levantamentos florísticos qualitativos. Cad Geociênc. 1994;12:39-43.

15 Windisch PG. Pteridófitas da região Norte Ocidental do Estado de São Paulo. Guia para estudos e excursões. 2a ed. São José do Rio Preto: UNESP; 1992.

16 Flora do Brasil 2020 em construção [Internet]. Rio de Janeiro: Jardim Botânico do Rio de Janeiro; 2018 [citado 2018 jun. 6]. Disponível em: http://floradobrasil.jbrj.gov.br/

17 Almeida TE, Sousa DCS, Costa EC, Salino A. Flora das cangas da Serra dos Carajás, Pará, Brasil: Polypodiaceae. Rodriguésia 2017;68:871-80. 
18 Rolim LB, Salino A. Polypodiaceae Bercht \& J. Presl (Polypodiopsida) no Parque Estadual do Itacolomi, Minas Gerais, Brasil. Lundiana 2008;9(2):83-106.

19 Silva AG, Schwartsburd PB. Ferns of Viçosa, Minas Gerais State, Brazil: Polypodiaceae (Polypodiales, Filicopsida, Tracheophyta). Hoehnea 2017;44(2):251-68.

20 Benzing DH. Vascular epiphytes. Cambridge: Cambridge University Press; 1990.

21 Bataghin FA, Muller A, Pires JS, Barros F, Fushita AT, Scariot EC. Riqueza e estratificação vertical de epífitas vasculares na Estação Ecológica de Jataí - área de Cerrado no Sudeste do Brasil. Hoehnea 2012;39(4):615-26.

22 Geraldino HCL, Caxambú MG, Souza DC. Composição florística e estrutura da comunidade de epífitas vasculares em uma área de ecótono em Campo Mourão, PR, Brasil. Acta Bot Bras. 2010;24:469 82.

23 Barros ICL, Cantarelli LC, Farias RP, Pereira AFN, da Silva IAA. Distribuição vertical de samambaias epífitas em um fragmento de Floresta Atlântica no Nordeste do Brasil. Iheringia, Sér. Bot. 2014;69(1):143-53.

24 Fraga LL, Silva LB, Schimitt JL. Composição e distribuição vertical de pteridófitas epifíticas sobre Dicksonia sellowiana Hook. (Dicksoniaceae), em Floresta Ombrófila Mista no sul do Brasil. Biota Neotrop. 2008;8:123-9.

25 Kersten RA, Kuniyoshi YS. Epífitos vasculares na bacia do alto Iguaçu - composição florística. Estud Biol. 2006;64:55-71.

26 Schneider PH, Schmitt JL. Composition, community structure and vertical distribution of epiphytic ferns on Alsophila setosa Kaulf., in a Semideciduous Seasonal Forest, Morro Reuter, RS, Brazil. Acta Bot Bras. 2011;25:557-65.

27 Roberts NR, Dalton PJ, Jordan GJ. Epiphytic ferns and bryophytes of Tasmanian tree-ferns: a comparison of diversity and composition between two host species. Austral Ecol. 2005;30:146-54.
28 Arévalo R, Betancur J. Vertical distribution of vascular epiphytes in four forest types of the Serranía de Chiribiquete, Colombian Guayana. Selbyana 2006;27:175 85.

29 Krömer T, Kessler M, Gradstein SR. Vertical stratification of vascular epiphytes in submontane and montane forest of the Bolivian Andes: the importance of the understory. Plant Ecol. 2007;189:261-78.

30 Kira T, Yoda K. Vertical stratification in microclimate. In: Lieth $\mathrm{H}$, Werger MJA, editors. Tropical Rain Forest Ecosystems. Amsterdam: Elsevier; 1989. p. 7-53.

31 Page CN. Ecological strategies in fern evolution a neoptendological overview. Rev Palaeobot Palynol. 2002;119:1-33.

32 Dubuisson JY, Schneider H, Hennequin S. Epiphytism in ferns: diversity and history. C.R. Biologies 2009;332:120-8.

33 Alves MEO, Brun C, Dal Forno RS, Essi L. Levantamento de espécies epífitas vasculares da zona urbana do município de Palmeira das Missões, RS, Brasil. Ciênc. Nat. 2014;3:268-76.

34 Sakagami CR. Pteridófitas do parque ecológico da Klabin, Telêmaco Borba, Paraná, Brasil [dissertação]. Curitiba (PR): Universidade Federal do Paraná; 2006.

35 Schwartsburd PB, Labiak PH. Pteridófitas do Parque Estadual de Vila Velha, Ponta Grossa, Paraná, Brasil. Hoehnea 2007;34:159-209.

36 Moram RC. The importance of mountains to pteridophytes, with emphasis on Neotropical montane forest. In: Churchill SP, Baslev $\mathrm{H}$, Forero E, Luteyn JL, editors. Biodiversity and conservation of Neotropical montane forests. New York: New York Botanical Garden Press; 1995. p. 359-63.

37 Tryon RM. Development and evolution of Fern Floras of Oceanic Islands. Biotropica 1970;2:76-84. 
38 Schimitt JL, Budke JC, Windisch PG. Aspectos florísticos e ecológicos de pteridófitas epifíticas em cáudices de Dicksonia sellowiana (Pteridophyta, Dicksoniaceae) em São Francisco de Paula - RS, Brasil. Pesqui., Bot. 2005;56:161-72.

39 Michelon C. Samambaias e Licófitas do Parque Estadual do Guartelá, PR, Brasil. Hoehnea 2013;40(2):191-204.

40 Sylvestre LS. Revisão taxonômica das espécies da família Aspleniaceae A. B. Frank ocorrentes no Brasil [tese]. São Paulo (SP): Universidade de São Paulo; 2001.

41 Vasques DT, Prado J. Campyloneurum C. Presl (Polypodiaceae) no Estado de São Paulo, Brasil. Hoehnea 2011;38:147-63.

42 Assis ELM, Labiak PH. Polypodiaceae da borda oeste do Pantanal Sul-Matogrossense, Brasil. Rev Bras Bot. 2009;32(2):233-47.

43 Martínez OG, Assis FC, Meza Torres EI, Cacharani DA, Jaimez DG. The genus Pecluma (Polypodiaceae) in Argentina. Darwiniana 2016; 4(2):234-51.

44 Sota ER. Polypodiaceae y Grammitidaceae Argentinas. Opera Lilloana 1960;5:1-229. 